Fourth International Conference on Sustainable Construction Materials and Technologies

http://www.claisse.info/Proceedings.htm

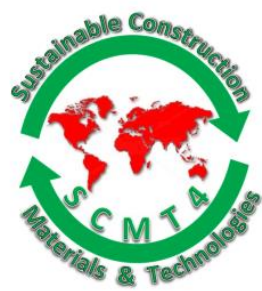

SCMT4

Las Vegas, USA, August 7-11, 2016

\title{
Distribution Analysis of Fiber into Bamboo Culms - A Natural Fiber for Being Used as Reinforcement
}

\author{
Luz Sanchez-Echeverri ${ }^{1 a}$, Jorge Medina-Perilla ${ }^{1 b}$, and Mario Rodriguez-Garcia ${ }^{2}$ \\ ${ }^{1}$ Facultad de Ingeniería, Departamento de Ingeniería Mecánica; Grupo de Materiales y Manufactura,

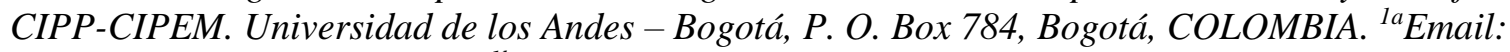 \\ <se.luz10@uniandes.edu.co>, ${ }^{1 b}$ Email::〈jmedina@uniandes.edu.co>. \\ ${ }^{2}$ Centro de Física Aplicada y tecnología Avanzada, Departamento de Ingeniería Mecánica; Universidad \\ Autónoma de México, Santiago de Qro, México. Email: 〈marioga@fata.unam.mx>.
}

\begin{abstract}
Nowadays, construction industry has ventured with eco-friendly materials. Into these new options there exists a set of materials known as cement composites whose reinforcement could be made with natural fibers. A fast-growth plant native from Colombia known as Guadua, a kind of Bamboo, has environmental and mechanical advantages over conventional construction materials. The use of a Bamboo as whole is important, but the use of their fibers has gained importance due to their potential to use as reinforcement into cement composite. This paper presents a study about characteristics of the fiber distribution into two Guadua's varieties: Guadua Angustifolia Kunth Rayada Amarilla and Guadua Angustifolia Kunth Macana. They were examined under scanning electronic microscopy, Xray diffraction and the Association Official Agricultural Chemist - 2000 methodology to get quantitative information about the insoluble fiber content. Findings indicated that the insoluble fiber distribution is not homogenous between the internal and external layer of bamboo culm; the fiber content inside of Guadua culms increases from inner to outer layer. X-ray patterns showed that the insoluble fiber has a preferential crystalline orientation in relation to the growth direction of bamboo. The combination of scanning electronic microscope and X-ray diffraction offers important information about the localization and morphologic distribution of components inside bamboo culms.
\end{abstract}

\section{INTRODUCTION|}

In the last three decades bamboo has been increased in importance around the world because of its mechanical, esthetic, and ecological properties make it versatile for many applications. The wide variety in appearance, mechanical properties and chemical composition are some of the reasons why bamboo is now very attractive for several purposes even than wood. Bamboo is a natural composite material that consists mainly in a long cellulose fiber joins by ligning matrix (Khosrow y Albanise, 2005; Jain et al. 1992). This structure is much stronger and stiffer than wood fiber and comparable in extensibility due to its unique cell wall structure (Yu et al. 2014).

Due to the outstanding Bamboo fibers properties, a new application has been developed in the last decades: composites, in which an organic or inorganic matrix is reinforced with this lingo-cellulosic 
material (da Costa Correia et al. 2016; da Costa Correia et al. 2014; Yu et al. 2014). This kind of applications requires a complete knowledge about bamboo fiber distribution and content into their culm. Distribution of the Bamboo cellulose fibers has been studied and it have been proved that is different across the internal to external wall (Khosrow y Albanise, 2005) and also depends of age culm diameter and the bamboo specie (Lo et al. 2004). Some researchers have studied the fiber distribution, chemical compounds of bamboo fibers and their correlation with mechanical behavior (Sanchez-Echeverri et al. 2014; Sanchez-Echeverri et al. 2010; Ahmad y Kamke, 2005; Ray et al. 2005; Obataya et al. 2007;).

Ahmad y Kamke, 2005 studied how factors such as age of the plant, location, and fiber extraction method affect the fiber properties. Costa Correia et al. (2015) have demonstrated that organosolv process is effective to obtain cellulosic pulp from bamboo culms. Okubo et al. (2004) studied the incorporation of bamboo fiber to development eco-composites materials in order to improve mechanical properties. Sigriccia et al. (2008) studied how the properties of natural fibers affect the mechanical properties of the composites materials. Despite of the aforementioned reports indicate that the bamboo fiber has an important role on different applications, their microstructural characterization is still unknown.

The bamboo fiber has two principal compounds: insoluble and soluble fiber. The first is constituted mainly by cellulose, hemicelluloses, and lignin while gums, mucilage and pectins constitute the soluble part. Toledo et al. (2006) reported starch into bamboo culms as another invited component. The traditional characterization of these kind of fibers have been made by microscopy methods, but the quantification of this fiber content into the culm has not been studied yet.

From the point of view of fiber used as reinforcement is very important to know how it is distributed into the culms; therefore, the objective of this paper is to show the fiber distribution content, morphological changes and crystalline orientation of fiber within the culm of two Guadua's varieties.

\section{EXPERIMENTAL INVESTIGATION}

\section{Sample description}

Bamboo samples were from an experimental field located on the Andean region of Colombia, harvested on February 15, 2009. Both Guadua Angustifolia Kunth (GAK) Rayada Amarilla and Macana were dried in a furnace at $40{ }^{\circ} \mathrm{C}$ for $8 \mathrm{~h}$ in order to reduce the moisture content and decrease the microorganism proliferation. The culms in these kinds of bamboos are hollow in the center as a cylinder and the wall thickness is in average $1.5 \mathrm{~cm}$. For some analysis was used the whole culm with two different directions defined as $\mathrm{z}$ and $\mathrm{y}$ - directions as shown in Figure 1a. In addition, the $\mathrm{z}$ - direction corresponds to the growth direction of the GAK while y- direction goes from the internal wall to external wall. In order to determine the fiber distribution and morphological changes into bamboo culm, the samples were cut in four equal sections along y direction as show in the Figure $1 \mathrm{~b}$.
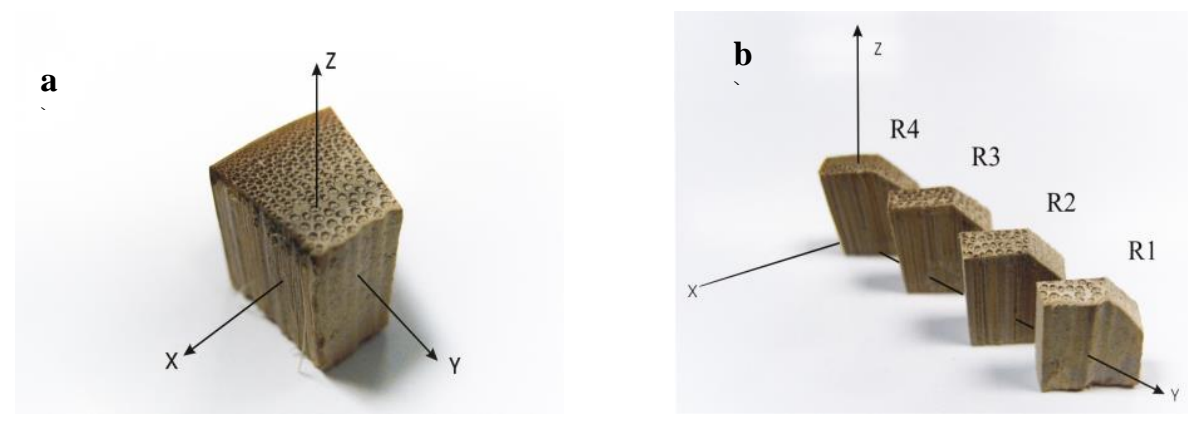

Figure 1. (a) Whole bamboo culm with z- and y-directions. (b) Four equal sections of a bamboo culm. 
Fiber determination. Insoluble fiber determination was done using the official Method 992.16, AOAC 2000 (Sigma Aldrich TDF-100A Kit, Saint Louis Missouri, USA) (AOAC 2000). The fiber study was carried out in the whole sample (Figure 1a) as well as in each one of the section showed in Figure 1b. All measurements were done by triplicate.

Scanning electron microscopy, SEM. The morphology analysis of the samples was performed with a low vacuum scanning electron microscope (LV-SEM, JSM 5600LV) with resolution of $5 \mathrm{~nm}$ in LV mode, fitted with an energy dispersive X-ray spectrometer (Noran model Voyager 4.2.3). Prior to the analysis, the samples were polished with different grain sizes of sandpaper, 400, 600 and 1200 (Fandeli SIC A-99$600,1200)$. It guaranteed that the machine cut do not affect the surface structure of the sample. After this process, the samples were cleaned to remove the sandpaper particles and the excess of organic materials. As organic material, it is necessary to cover them with a gold layer in order to make them conductive and obtain resolved SEM images. The samples were fixed on the specimen holder with carbon tape and mounted on a cupper specimen holder. The analyses conditions used were $15 \mathrm{kV}$ electron acceleration voltages and 12-20 $\mathrm{Pa}$ of pressure in the specimen chamber with the backscattering electron signal. The analysis was done for the whole sample and the four equal cuts showed in the Figure 1a and b.

X-ray diffraction. X-ray Diffraction patterns of GAK Macana and Rayada Amarilla were done as follow: the first study was carried out in the two directions shown in Figure 1a as well as for each one of the internal faces of the samples showing in Figure 1b. The analysis of the crystalline structures of Guadua were recorded on a diffractometer (Siemens D5000) operating at $35 \mathrm{~K}$ and $15 \mathrm{~mA}$, with $\mathrm{Cu} \mathrm{K} \alpha$ radiation wavelength of $\lambda=1.5406 \AA$. Data was collected from $4^{\circ}$ to $70^{\circ}$ on a $2 \theta$ scale with a step size of $0.05 \mathrm{~s}$. The measurements were made at room temperature.

\section{RESULTS AND DISCUSSIONS}

Fiber determination. The total fiber consists in a complex carbohydrates complex, comprising various amounts of cellulose, hemicellulose, pectin and lignin (Selvendran, 1984). Those compounds could be classified in two great groups of components: soluble and insoluble fiber. The insoluble fiber is composed mainly by cellulose, some lignin, and hemicelluloses (Pereira et al. 2004). While soluble fiber is composed by gums, pectins, and mucilages. Table 1 shows the soluble and insoluble fiber content for whole Guadua samples (Figure 1A).

Table 1. Insoluble and soluble fiber content of bamboo culm for Guadua Angustifolia Kunth Macana and Rayada Amarilla

\begin{tabular}{|c|c|c|}
\hline Sample & Insoluble Fiber (\%) & Soluble Fiber (\%) \\
\hline Macana & $74,41 \pm 0,23$ & $10,6 \pm 0,35$ \\
\hline Rayada Amarilla & $83,22 \pm 0,04$ & $2,16 \pm 0,06$ \\
\hline
\end{tabular}

The results showed in table 1 are agree with Liese, 1992 who argued that the most compound into the Guadua culm is insoluble fiber. He showed that parenchymal cells make up nearly $60 \%$ of a bamboo volume, and other $20 \%$ are constituted by Bamboo fibers and both, parenchyma and bamboo fiber are composed by insoluble fiber.

The insoluble fiber content was determined for each segment throughout radial of Guadua culm (Figure 1b). Figure 2 shows the insoluble fiber content distribution across the culm for GAK Macana and Rayada Amarilla. The results displayed in this figure correspond to five measurements per point. 


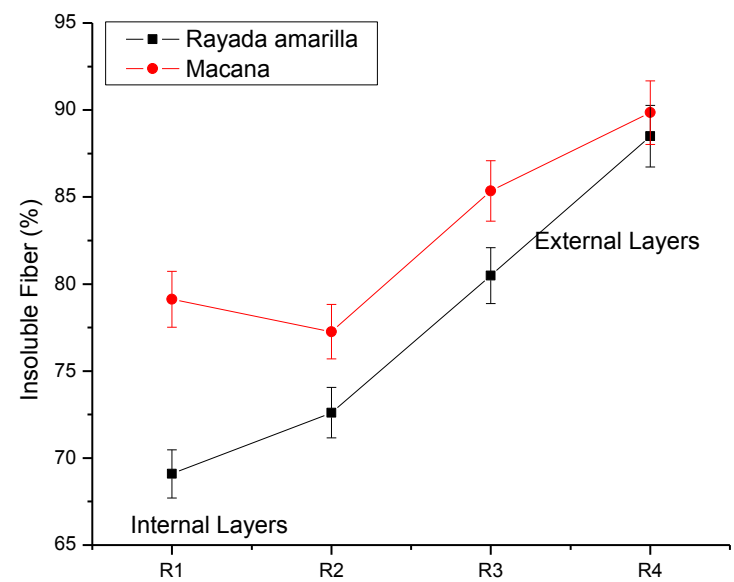

Figure 2. Fiber distribution across Bamboo culm from internal to external layer

According to those results the most external layers of the culm possess the higher insoluble fiber content and this concentration increases from the internal to the external layers. Is also possible define from the figure 2 that GAK Macana has a higher insoluble fiber content in each bamboo culm section than GAK Rayada Amarilla; however, as a whole the insoluble fiber content is higher in GAK Rayada Amarilla. These results are in according with Khosrow y Albanise, 2005; they have been studied the fiber distribution across the thickness culm using optic and electronic microscopy techniques. The knowledge of fiber distribution throughout its culm is a very important fact because with this information it is possible to establish the potential uses for each one of the culm sections.

Scanning electron microscopy. In order to have an idea for the variation in the internals components into bamboo culms, several micrographies were taken. Figure 3 shows the 3D SEM image of GAK Rayada Amarilla took at $13 \mathrm{x}$ In this figure is possible to see how the tissues around the vascular bundle are becoming more compact across the bamboo culm from the internal to the external wall. It is well known that in this tissue are located the bamboo fibers (Shigeyasu et al. 1996), therefore; is clear that the fiber distribution into bamboo culm increases across the internal to the external layer as it is indicated by the arrow. Lo et al. (2004) demonstrated that fiber density affects strength capacity bamboo; therefore, it could be possible that the external part of bamboo has more strength than the internal part. Another important feature on this SEM image is that these fibers have a longitudinal orientation and this behavior could be related with the orientation of the fiber compounds.

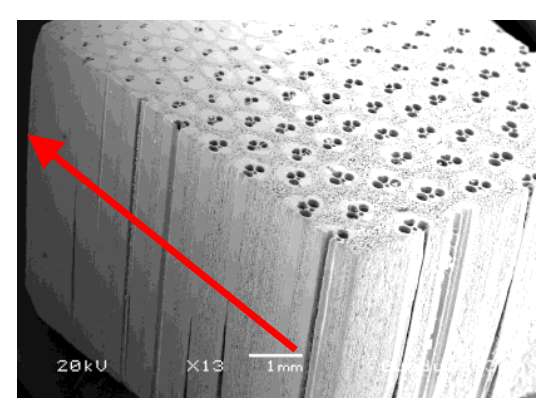

Figure 3. SEM image (13X) bamboo culm Guadua Angustifolia Kunth Rayada Amarilla

It is very important to establish the reason why the insoluble fiber content changes as function of the radius. Those changes should be related with morphological conformation of each one of these sections in special with the content of starch, cellulose, hemicellulose, and gums that they are the main fiber compounds. 
In order to know how the morphology across the culm is changing, SEM analysis of the four sections of culm shown in the Figure 1B was performed. Figure 4a-d shows the morphological structures found for the four sections of GAK Rayada Amarilla, called R1, R2, R3, and R4; the same structures were found in GAK Macana. For all sections in both bamboo culms is possible to see a rectangular network with semispherical structures within them. These networks are the parenchyma cell (Liese, 1998) and they do not have the same dimension in each of the four sections. The changes of the cell dimension explains the variation of fiber content across the culm, due to the main compound in those cells is cellulose. The semispherical structures were identified as starch (Toledo et al. 2006) and section R3 showed the major quantity of this structures (Figure 4C). The starch granules into the bamboo vary from 3 to $10 \mu \mathrm{m}$ with semispherical and polygonal shapes; this result agrees with the starches found by Toledo et al. (2006).
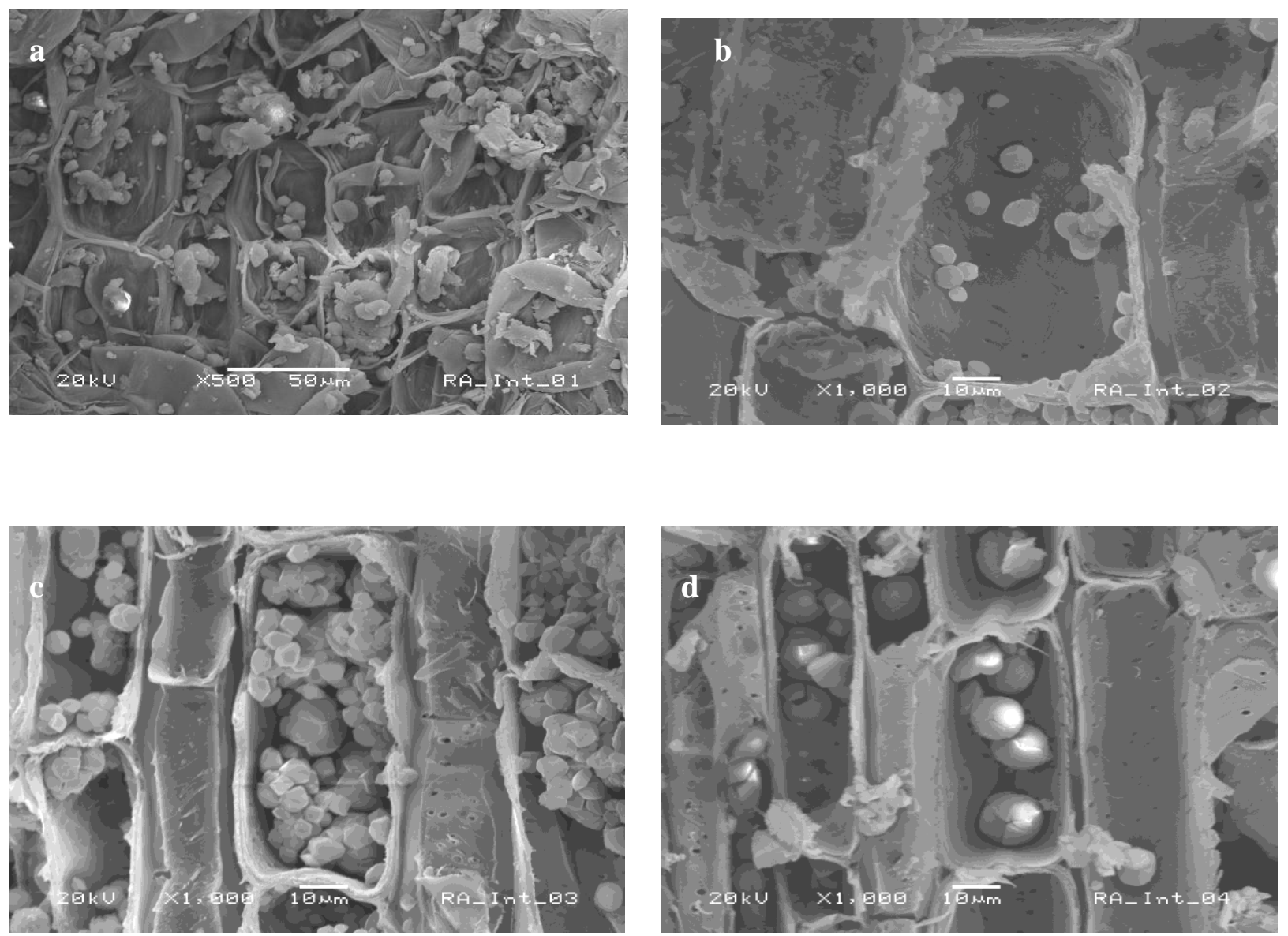

\section{Figure 4. Morphological variation across bamboo culm section of Guadua Angustifolia Kunth Rayada Amarilla. 4a) Section R1; 4b) Section R2; 4c) Section R3 and 4d) Section R4}

Figure $5 \mathrm{a}$ and $\mathrm{b}$ shows the starch granules into the parenchyma cells for GAK Macana and Figure $5 \mathrm{c}$ and $\mathrm{d}$ shows the starch granules into the parenchyma cells for GAK Rayada Amarilla. A noticeable point is that in the case of GAK Macana the starch granules are spherical with dimension between 3 and $10 \mu \mathrm{m}$ located in separated way while in the case the starch granules present in the GAK Rayada Amarilla those are in agglomerates formed by polygonal starch granules with dimension around $5 \mu \mathrm{m}$. The identification of these structures shown in Figure 4 and 5, identified as starch, can be used for a characterization X-ray diffraction by the direct identification of amylose due to the starch granules are formed by two molecules known as Amylose and Amylopectin cover by a protein matrix, a detail description of the structural and morphological features of corn starch granules has been done recently by Rojas-Molina et al. (2007). 

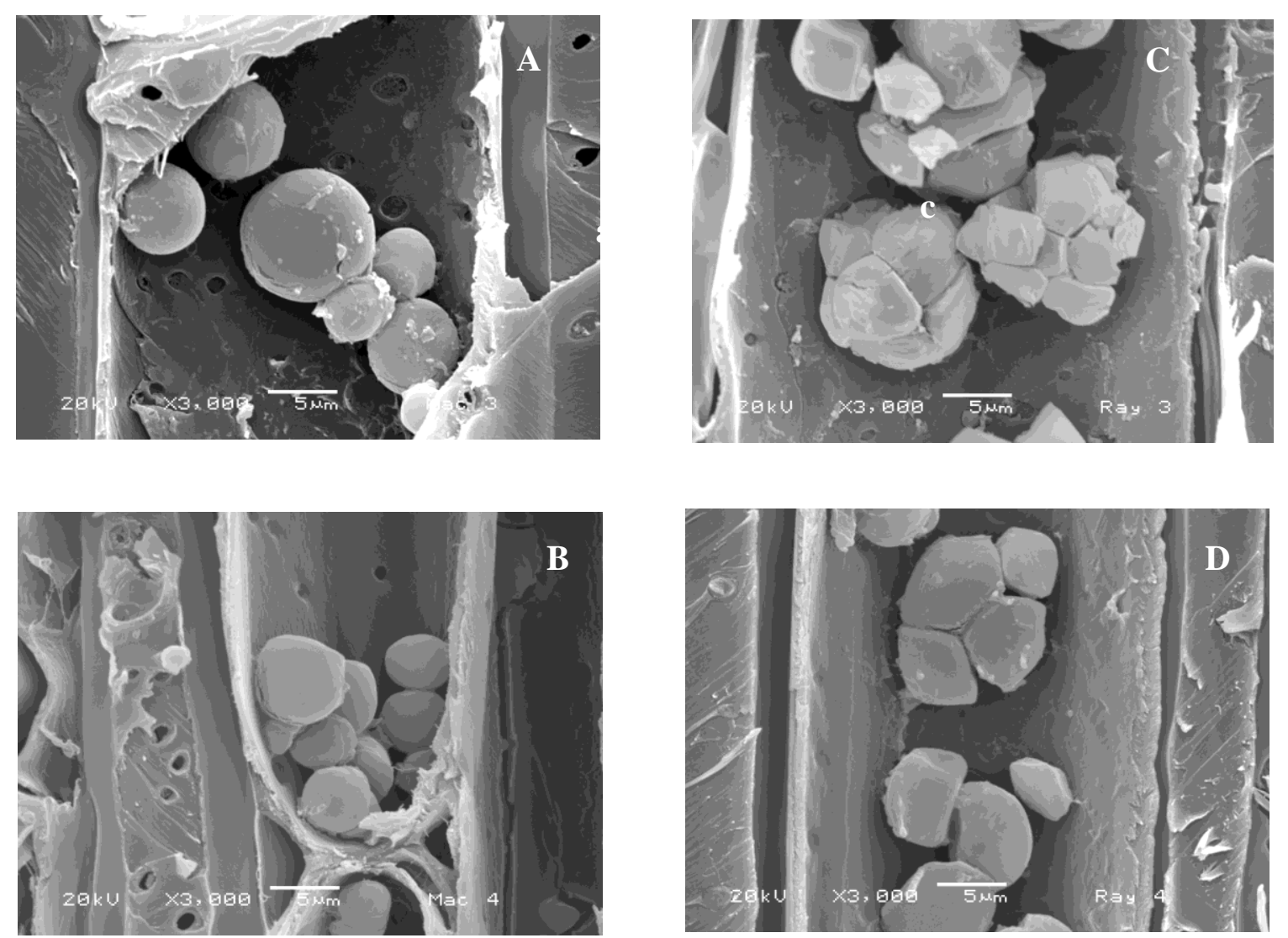

Figure 5. Starch granules in (a-b) Guadua Angustifolia Kunth Macana (c-d) Guadua Angustifolia Kunth Rayada Amarilla

The bamboo characterization by SEM is a powerful tool because permits to identify and classify different Bamboo culms, and also it serves to establish, according with the final use of this material, the best bamboo variety, and best part of the culm

\section{X-Ray Diffraction}

In the Bamboo culm is possible to identify two directions ( $\mathrm{z}$ and $\mathrm{y}$ directions), in both directions is possible to find the same chemicals compounds, however due to the anisotropy of this material; these compounds could be organized differently. The insoluble fiber is composed mainly by cellulose, and due to its crystalline structure it is possible identify it using X-ray diffraction technique, but other compounds such as lignin and hemicellulose are amorphous and it is not possible to establish a crystalline direction (Khosrow y Albanise, 2005). In order to determine what compounds form the diffraction patterns into the Bamboo culm, native-cellulose patterns and starch patterns were used to identify them. Andress (1928) classified native cellulose as monoclinic lattice. He also published the International Diffraction Data classified it with the patter number 00-003-0289. On the other hand, Imberty et al. (1988) published the possible structure crystalline of $\alpha$-amylose and the International Diffraction Data classified this pattern with the patter number 00-043-1858.

Figure 6 shows the X-Ray Diffraction patterns of GAK (a) Rayada Amarilla and (b) Macana both for $\mathrm{z}$ and y directions (Figure 1a). Continuous lines in this figure represent the identification of different crystalline orientations for native cellulose and amylose. According to these results it is clear that GAK Rayada Amarilla and Macana have the same components in both directions but these components, native cellulose and amylose have different preferential crystalline orientation. 


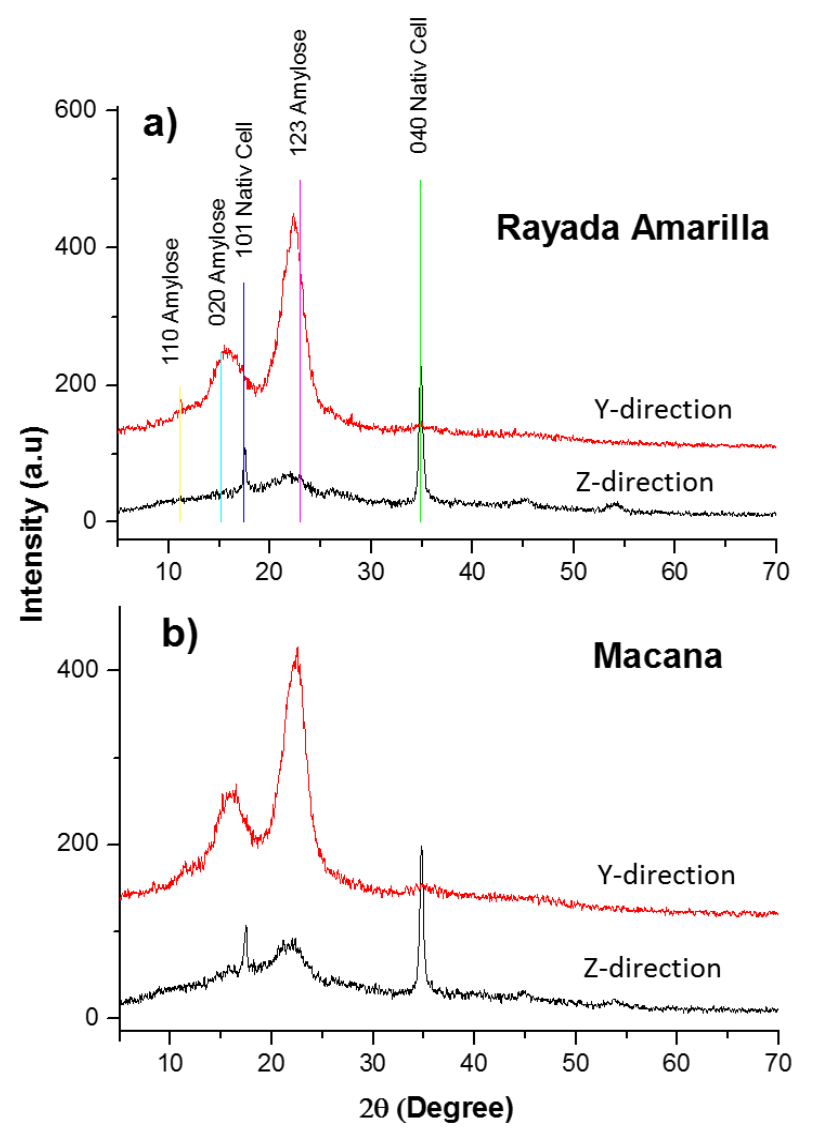

Figure 6. X- Ray diffraction patterns to Guadua Angustifolia Kunth a) Rayada Amarilla and $b)$ Macana in two directions ( $z$ and $y$ directions)

These results demonstrate that the main crystalline contribution of the X-ray Diffraction patterns of GAK is coming from one of the components of the insoluble fiber that can be identified as cellulose. It is possible to see how the cellulose shows a defined orientation in transverse direction which is the growth Bamboo direction. The results shown in Figure 6 can be related with the SEM images shown in Figure 4 because the main contribution of the X-ray pattern for the $\mathrm{y}$-direction is mainly made by amylose one of the compounds of starch. Despite amylopectin has not been identified in the International Diffraction Data, Rojas-Molina et al. (2007) proposed that amylopectin can be identified with the detection of the following peaks: $15.214^{\circ}$ and $21.154^{\circ}$. The inspection of the X- ray patterns shown in Figure 6 let establish us that in the studied samples the starch granules are formed mainly by amylose. Also, another important point is that the composition of those starch granules is similar for both bamboo varieties even though its morphology is different

Figure 7 show the X-ray diffraction patterns of Guadua Angustifolia Kunth (a) Rayada Amarilla and (B) Macana for the four sections identified as R1, R2, R3, and R4 (Figure 1B.). It is possible to see that the chemicals compounds: Cellulose (C) and Amylose (A) within bamboo culms do not have the same distribution and preferential orientation. Other important point in this figure is that the internal layers R1 for both bamboo samples have the most disorganized configuration in these chemical compounds, which agrees with the SEM images showing in the Figure 4. The X-ray diffraction patterns are also in according to the image shown in Figure 4C. Moreover, the section R3 shows the peaks more intensive, and as was mentioned before, in this region there is a considerable quantity of the starch, and this could influence the intensity of X-ray pattern. 


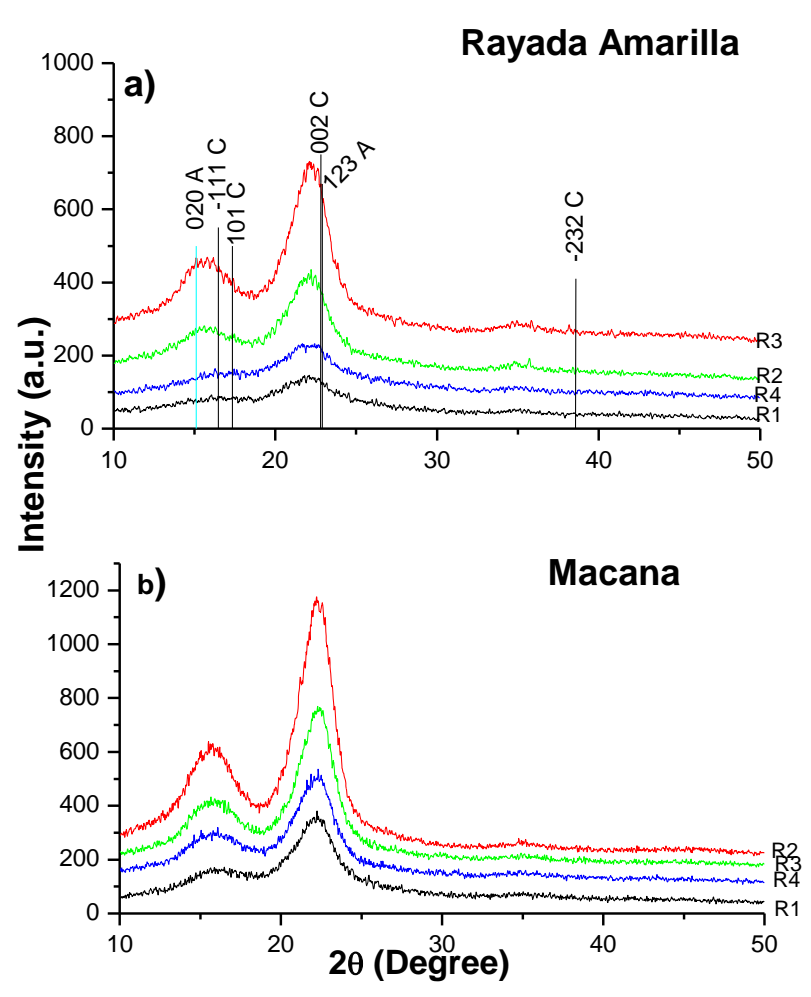

\section{Figure 7. X- Ray diffraction patterns to Guadua Angustifolia Kunth Rayada Amarilla (A) and Macana (B) on four sections trough the culm}

The most important point illustrated in Figure 6 and Figure 7 is that cellulose has preferential growth direction and has a not uniform distribution, for any application with bamboo fiber these results are important and could assist in the variety selection of the GAK, and to choose a special section of the culm in order to have a benefit extract the fiber bamboo.

\section{CONCLUSIONS}

The soluble and insoluble fiber content was quantified for the macro whole specimens of Guadua Angustifolia Kunth and in microscale along his radius.

The soluble and insoluble fiber content across the culm in both varieties of Guadua Angustifolia Kunth is not uniform. Insoluble fiber content increases while soluble fiber content decreases from internal to external wall. However, Guadua Angustifolia Kunth Rayada Macana has more insoluble-fiber content than Guadua Angustifolia Kunth Rayada Amarilla in each section along the radius.

The composition of starches in both varieties of Guadua Angustifolia Kunth is similar as was shown by $\mathrm{X}$-ray patterns; even though, their morphology is different as was determined in the Scanning Electronic Microscopy images. Moreover, SEM images showed that starches are not structural part in the Guadua configuration, due to they are located inside of cells.

The cellulose within bamboo culms has a preferential orientation in the crystalline directions 040 and 101 . This preferential orientation is related with the Bamboo growth direction as was shown in X-Ray patterns 


\section{ACKNOWLEDGEMENTS}

Luz Adriana Sánchez Echeverri wants to thanks to COLCIENCIAS for the support in her Doctoral studies. The authors of this paper want to thank to MsC. Alicia del Real, Antonio and PhD Margarita Contreras for their technical support and University of Quindio, Colombia for the samples used in this study.

\section{REFERENCES}

Ahmad, M; Kamke, FA 2005, Analysis of Calcutta bamboo for structural composite materials: Physical and mechanical properties, Wood Sci Technol, vol. 39, pp.448-459.

Andress, KR 1928, About the action of moderately concentrated nitric acid on cellulose, Phys. Chem, vol.136, pp. 279-288.

AOAC-2000. Official Methods of Analysis of the Association of Official Analytical Chemists, 17th Ed. Method 992.16 The Association: Gaithersburg, MD.

Da Costa-Correira, V, Da Silvia-Curvelo, AA, Marabezi, K, De Souza-Almeida, AEF, Savastano-Junior, H 2015, Bamboo cellulosic pulp produced by the etanol/water process for reinforcement applications, Ciênc. Florest, vol.25 no.1, pp. 127-135.

Da Costa-Correira, V, Santos, SF, Mármol, G, Da Silvia-Curvelo, AA, Savastano-Junior, H 2014, Potential of bamboo organosolv pulp as a reinforcing element in fiber-cement materials. Construction and Building Materials, vol. 72, 65-71.

Da Costa-Correira, V, Maria-Siqueira, F, Donizetti-Dias, R; Savastano-Junior, Holmer 2016, Macro, micro and nano scale bamboo fiber as a potential reinforcement for composites, Key Engineering Materials, vol. 668, pp. 11-16.

Imberty, A; Chanzy, H; Perez, S; Burleon, A; Tran, V 1988, The double-helical nature of the crystalline part of A-starch, J. Mol. Biol, vol. 201, pp.365-378.

Jain, S; Kummar, R; Jindal, UC 1992. Mechanical behaviour of bamboo and bamboo composite. J Matter Sci, vol. 27, pp. 4598-604.

Khosrow, G.; Albanise, BM 2005, Propiedades fisicas e mecânicas do colmo inteiro do bamboo da espécie Guadua angustifólia. Revista Brasileira de Engenharia Agrícola e Ambiental, vol.9, pp.107114.

Liese, W. The anatomy of bamboo culms. BRILL 1998.

Liese, W. (1992). Bamboo and its use. International Symposium on Industrial Use of Bamboo, Beijing, China. $7-11$.

Lo, T; Cui, HZ; Leung, HC 2004, The Effect of fiber density on strength capacity of bamboo. Materials Letters, vol. 58, pp. 2595-2598.

Obataya, E; Kitin, P; Yamauchi, H 2007, Bendind characteristics of bamboo (Phyllostachys pubescens) with respect to its fiber-foam composite structure. Wood Sci Technol, vol.41, pp. 385-400.

Okubo, K; Fujii, T; Yamamoto, Y 2004. Development of bamboo-based polymer composites and their mechanical properties. Composites Part A, vol. 35, pp. 377-383.

Pereira, MA; et al, 2004, Dietary fiber and risk of coronary heart disease, Arch Intern Med, vol. 164, pp 370-376. 
Ray, AK; Mondal, S; Das, SK; Ramachandrarao, P 2005. Bamboo: A functionally graded compositecorrelation between microstructure and mechanical strength. J of Materials Science, vol.40, pp. 52495253.

Rojas-Molina, I; Gutierrez-Cortez, E; Palacios-Fonseca, A; Baños L; Pons-Hernandez, JL; GuzmánMaldonado, SH; Pineda-Gomez, P; Rodríguez, ME 2007, Study of Structural and Thermal Changes in Endosperm of Quality Protein Maize During Traditional Nixtamalization Process. Cereal Chem, vol. 4, pp. 04-312.

Sanchez-Echeveri, LA; Contreras-Padilla, M; Rodriguez-Garcia, ME 2010. A correlation between soluble and insoluble fiber with the elastic modulus in four varieties of bamboo. MRS Symp. Proc, vol.1277.

Sanchez-Echeveri, LA; Aita, G, Robert, D, Rodriguez-Garcia, ME 2014. Correlation between chemical compounds and mechanical response in culms of two different ages of Guadua angustifolia Kunth. Madera y Bosques, vol. 20, no 2, pp. 87-94.

Shigeyasu, A; Tamotsu, M; Yukito, N; Yoshinobu, I; Atsushi, K; Yang, Z 1996. The Mechanical Structures of Bamboos in Viewpoint of Functionally Gradient and Composite Materials. J Composites Materials, vol. 30, pp. 800-819.

Sgriccia, N; Hawley, MC; Misra, M 2008. Characterization of natural fibers and natural fiber composites. Composites: Part A, vol. 39, pp. 1632-1637.

Selvendran, RR 1984. The plant cell as a source of dietary fiber: Chemistry and structure, Am J Clin Nutr, vol. 39, pp. 320-337.

Toledo, MC, Azzini, A, Reyes, F. G. Isolation and Characterization of Starch from Bamboo Culm (Guadua flabellate). Starch, v.39, p.158-160, 2006.

Yu, Y, Wang, H, Lu, F, Tian, G, Lin, J 2014. Bamboo fibers for composite applications: a mechanical and morphological investigation. J Mater Sci, vol. 49, pp. 2559-2566. 